\title{
I dentification of death receptors DR4 and DR5 in HTB-12 astrocytoma cell lines and determination of TRAI L sensitivity
}

\author{
Elenia Riddick, Shavonda Evans, J effrey Rousch, Ephraim Gwebu, Hirendra Nath Banerjee \\ Department of Biological and Pharmaceutical Sciences, Elizabeth City State University campus of The University of North \\ Carolina, Elizabeth City, NC / USA.
}

Correspondence: Hirendra Nath Banerjee. Address: Department of Biological and Pharmaceutical Sciences, Elizabeth City State University campus of The University of North Carolina. Jenkins Science Center, 1704 Weeksville Road, Elizabeth City, NC 27909, USA. Email: BHIRENDRANATH@MAIL.ECSU.EDU

Received: September 12, 2013 Accepted: November 5, 2013

Online Published: November 17, 2013

DOI : $10.5430 /$ jst.v3n6p20

URL: http://dx.doi.org/10.5430/jst.v3n6p20

\section{Abstract}

Astrocytomas are tumors which arise from astrocytes, cells that form the blood-brain barrier. There are very few drugs that successfully treat brain tumors. In this study, the cytotoxic effects on the HTB-12 astrocytoma cell line by tumor necrosis factor-related apoptosis-inducing ligand (TRAIL) were studied.

The presence of the TRAIL receptors, Death receptor 4 (DR4) and Death receptor 5 (DR5), were detected in HTB-12 cells by Enzyme-Linked Immunosorbent Assay (ELISA). Cytotoxicity assay by Trypan Blue Exclusion Method showed effective cell killing by TRAIL treatment. Thus, the presence of death receptors and TRAIL efficacy raises the therapeutic potential for this type of brain tumor.

\section{Key words}

TRAIL, Astrocytoma, Death receptors, Astrocytes

\section{Introduction}

Tumors that arise from astrocytes are known as astrocytomas. These tumors can be found within the brain or spinal cord and not in any other part of the body. Fifty percent of high-grade gliomas are formed due to mutation or deletion of the tumor suppressor gene $\mathrm{p} 53$, which is activated by DNA damage ${ }^{[1,2]}$. Astrocytomas are the most common malignant brain tumors in middle-age adults ${ }^{[3]}$. The only effective options for treatments available to this type of brain cancer patients are surgery and radiation therapy. Since very few drugs can cross the blood brain barrier and have effective therapeutic effects on this cancer, search for an effective therapeutic agent is important.

TRAIL is a member of the cytokine tumor necrosis factor (TNF) superfamily ${ }^{[4-6]}$. The TNF family plays a role in immune regulation and, once bound to TNF receptors, cause cell differentiation, cell proliferation and apoptosis. TRAIL, which was identified and cloned in $1995^{[7]}$, is a protein consisting of 281 amino acids, with the gene existing on chromosome number 3 (3q26). TRAIL is a type II membrane protein, due to its having a 7 transmembrane domain and no leader sequence, with an intercellular N-terminal and extracellular C-terminal, and C-terminal similar to other members within 
the TNF family. TRAIL is different from other members of the TNF family in that it only causes apoptosis in cancerous cells. TRAIL mRNA expression has been detected in various tissues, such as lymph nodes, spleen, thymus, lungs, placenta, small bowel, large bowel, prostate gland, and ovaries, but there is no expression in the liver. Other members of the TNF family are expressed in specific or limited types of tissues ${ }^{[8]}$. TRAIL also plays a role in tumor surveillance ${ }^{[9]}$.

Five receptors for TRAIL have been identified. They are all type I membrane proteins ${ }^{[10]}$ and their genes are located on chromosome 8 (8p21-22). The receptors for TRAIL are located on the surface of the cell and they can be found with or without the intracellular death domain. The receptors DR4 (TRAIL-R1), which is composed of 468 amino acids, and DR5 (TRAIL-R2), which is composed of 411 amino acids, are $58 \%$ homologous, contain a cytoplasmic death domain and are found in the vast majority of tissues ${ }^{[10,11]}$. This is contrary to DcR1 (TRAIL-R3), which is composed of 299 amino acids and DcR2 (TRAIL-R4), which is composed of 386 amino acids. Both DcR1 and DcR2 do not have a cytoplasmic death domain and are found in a limited number of tissues and normal cells ${ }^{[8,11-13]}$. Osteoprotegerin has also been identified as a non-inducible apoptosis receptor for TRAIL and is involved in the regulation of bone density ${ }^{[14]}$. Among the TRAIL receptors, DR4 was the first identified and DR5 was later identified due to its homology with DR4 ${ }^{[7]}$. Both of these receptors have received the name of death receptors because they contain death chambers or death domains, whereas the other receptors do not. Death domains are protein-protein motifs, which cause the formation of a signaling complex that recruit caspases, which then cause the induction of the cell death pathway ${ }^{[15]}$. Both of these receptors also contain extracellular cysteine rich domains with two cysteine-rich motifs, which is a similarity among all members of the TNF family.

TRAIL kills cancerous cells by causing apoptosis, which is a process by which cells internally activate "suicide" factors that will lead to its death ${ }^{[4]}$. Apoptosis results in separation of the cell membrane, DNA fragmentation, shrinking of the cell and disruption of the cytoskeleton and nucleus. Apoptosis is a necessary physiologic process by which organisms keep the proper number of cells alive and kill unnecessary cells. A malfunction in this process could result in more cells than needed within the organism leading to conditions that are life-threatening, such as the development of cancer ${ }^{[15]}$. Apoptosis can be initiated by intrinsic and extrinsic factors such as the binding of TRAIL, an apoptosis inducing ligand, and, in contrast to other regulators which cause apoptosis in both normal and cancerous cells, TRAIL has been identified as one of the regulators of apoptosis in tumor cells ${ }^{[8]}$.

\section{Materials and methods}

Cell Culture: The cell line that was used in this study was HTB-12 [American Type Culture Collection (ATCC), Manassas, VA]. A. Leibovitz at the Scott and White Clinic in Temple, Texas initiated the HTB-12 cell line in 1975. This cell line was started from an astrocytoma removed from a 72-year-old Caucasian male. ATCC received this cell line in January 1982 while in its twenty-third passage ${ }^{[16]}$. Astrocytomas were cultured in complete Leibovitz 15 (L-15) medium (ATCC) ${ }^{[16]}$, which consisted of L-15 medium supplemented with L-glutamine, 10\% Fetal Bovine Serum (FBS) and penicillin-streptomycin $(100 \mu \mathrm{g} / \mathrm{ml})$.

Human astrocytes cells were a kind gift from Dr. K. Pahan of University of Nebraska Dental School (Lincoln, NB). Astrocyte cells were cultured in DMEM-F12 medium supplemented with 10\% Calf serum and Penicillin-Streptomycin at $37^{\circ} \mathrm{C}$ in a carbon dioxide incubator.

Protein Assay: The protein concentrations for the samples were estimated using the Bicinchoninic Acid Protein (BCA) Assay performed according to manufacturer's instructions (Life Technologies Inc., Carlsbad, CA). Cells were lysed with Profound Lysis Buffer (Pierce, Rockford IL) and incubated on ice for $30 \mathrm{~min}$. After incubation, standards were set up according to the manufacturer's instructions and $0,20,40,60,80,100 \mu \mathrm{l} \mathrm{BCA}$ was added to $15 \mathrm{ml}$ conical tubes and diluted with $\mathrm{dH} 20$ to a final of $100 \mu \mathrm{l}$. Subsequently, standards and samples were incubated for $30 \mathrm{~min}$ in a $37^{\circ} \mathrm{C}$ water 
bath. After incubation the sample and standards were analyzed using a spectrophotometer at $562 \mathrm{~nm}$ wavelength (Spectronic 601, Milton Roy, Ivyland, PA).

ELISA: ELISA (Enzyme-Linked Immunosorbent Assay) was used to detect DR4 and DR5 receptor protein in the astrocytomas and astrocytes. Cells were trypsinized from confluent $25 \mathrm{~cm}^{2}$ flasks to conduct the DR4 and DR5 ELISA (Cell Sciences, Canton, MA; BioSource, Carlsbad, CA). Cells were removed, lysed with Lysis Buffer and incubated on ice for $30 \mathrm{~min}$. After incubation the BCA Assay was performed to estimate protein concentrations in the cell extracts used for the ELISA. Standards were set up for the DR4 and DR5 ELISA according to the manufacturer's instructions for DR4 and DR5 ELISA kits. Samples (cancer and normal cell lysates) were added to the ELISA plate to give a final concentration of $5 \mu \mathrm{g} / \mu \mathrm{l}$ of protein. The 96 well plate was read using an ELISA plate reader (MR600 Dynatech Microplate Reader) at 450 $\mathrm{nm}$ to determine the relative concentration of DR4 and DR5.

TRAIL cytotoxicity studies: This study was conducted using recombinant human TRAIL protein (PeproTech, Rocky Hill, NJ). Cells were grown in $35 \mathrm{~mm} \times 10 \mathrm{~mm}$ plates containing an equal number of cells. Following treatments, cells were maintained at $37^{\circ} \mathrm{C}$ for the duration of the experiments. Various concentrations of TRAIL $(0,1,100,200 \mathrm{ng} / \mathrm{ml})$ were added to cells for 4 hours ${ }^{[17]}$. TRAIL ( $1 \mathrm{ng}$ ) was added to cells for various time periods $(4,8,20,24$ hours). Cell death was assayed by the Trypan Blue Exclusion Method using a hemocytometer and inverted microscope.

Statistical Analyses: Each experiment was performed three times. ELISA data were analyzed using procGLM of the SAS Statistical Package (Cary, NC) and means separated using Fischer Protected LSD $(\alpha=0.05)$. Data regarding the effects of various concentrations of TRAIL on HTB-12 cells were analyzed using one way ANOVA and t-Test $(\alpha=0.05)$.

\section{Results}

In the present study, both normal human astrocytes and HTB-12 cells were tested for the presence of DR4 and DR5.

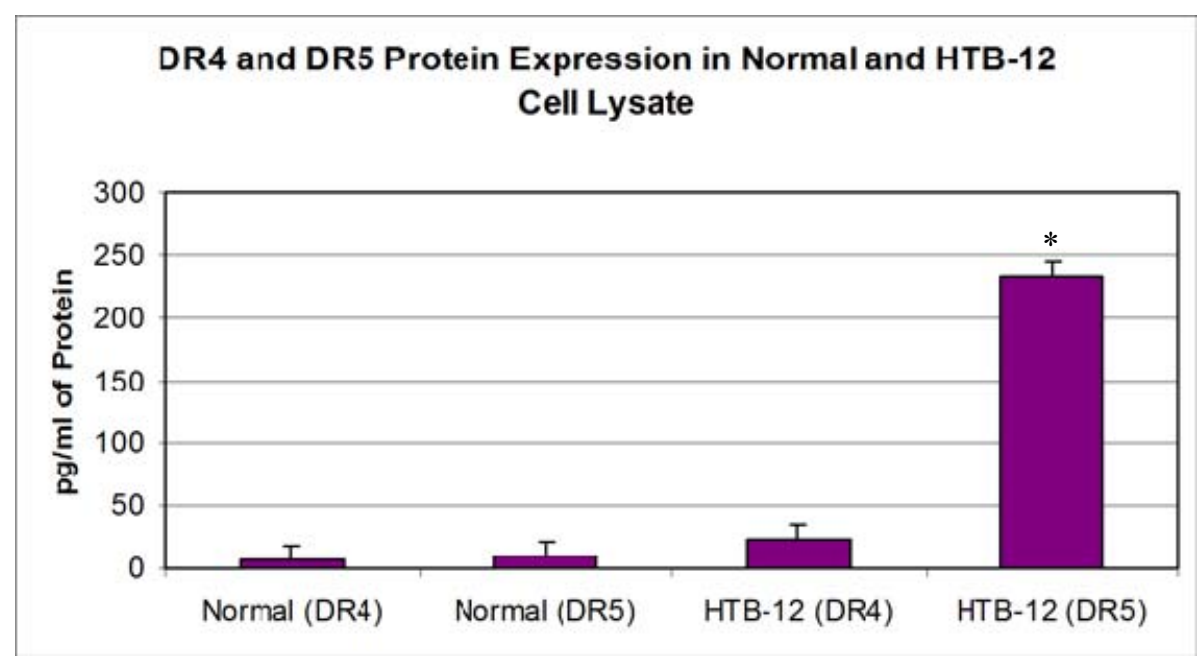

Figure 1. ELISA results for DR4 and DR5 using human normal astrocytes lysates and HTB-12 cell lysates. Samples (normal cell lysates and HTB-12 lysates) were added to the ELISA 96 well plates at a concentration of $5 \mu \mathrm{g} / \mu \mathrm{l}$ protein determined by BCA Assay and analyzed on a plate reader at $450 \mathrm{~nm}$. Asterisk indicates significantly different mean determined by Fischer Protected LSD $(\alpha=0.05)$ (Table 1).

To show the ability of TRAIL to bind to HTB-12 cells, the detection of the receptors was documented via ELISA. ELISA results showed that the receptors were present in all cell lines, however, expression of DR5 was greater than DR4 in 
HTB-12 (Figure 1). DR4 expression in astrocytes and astrocytoma was not significantly different, but DR5 expression was significantly greater than in DR4 and DR5 expression in normal cells and DR4 expression in HTB-12 cells (Table 1).

Table 1. Expression of DR4 and DR5 protein in normal human astrocytes and HTB-12 cell lysate as determined by ELISA using $5 \mu \mathrm{g} / \mu \mathrm{l}$ of protein for all samples on a 96 well ELISA plate read at $450 \mathrm{~nm}$. Means with the same letter are not significantly different $(\alpha=0.05)$.

\begin{tabular}{ll}
\hline Cell and receptor & Mean \pm std. \\
\hline HTB-12 DR5 & $233.33 \pm 7.4 \mathrm{a}$ \\
HTB-12 DR4 & $24.00 \pm 11.4 \mathrm{~b}$ \\
Human normal astrocytes DR5 & $10.33 \pm 8.4 \mathrm{~b}$ \\
Human normal astrocytes DR4 & $7.00 \pm 2.7 \mathrm{~b}$ \\
\hline
\end{tabular}

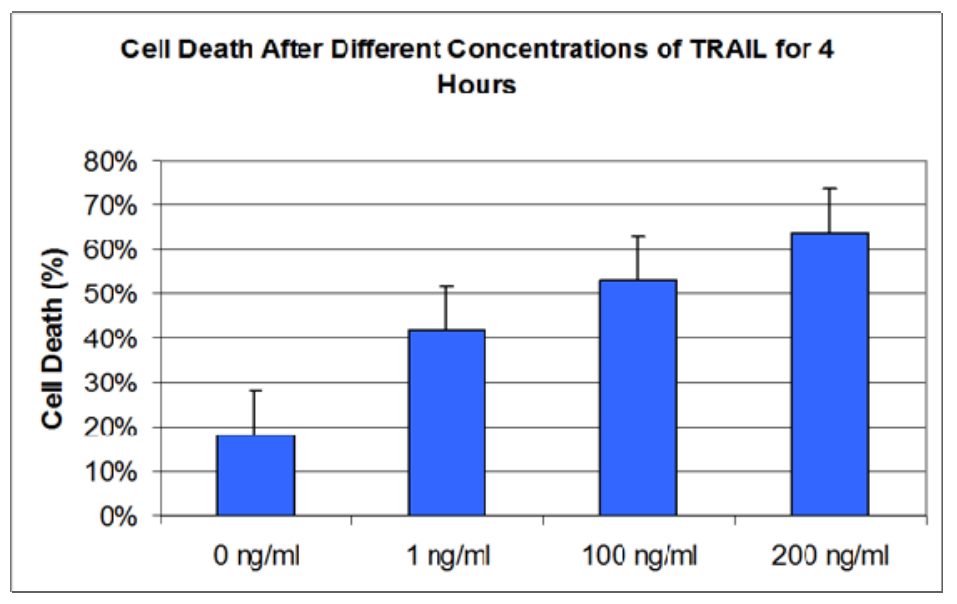

Figure 2. HTB-12 cell death after exposure to various concentrations of TRAIL for 4 hours at $37^{\circ} \mathrm{C}$. Cell death was assayed using the Trypan Blue Exclusion Method and direct count using a hemocytometer. All means are statistically different from each other ( $\mathrm{t}-$ Test, $\alpha=0.05$ ) (Table 2).

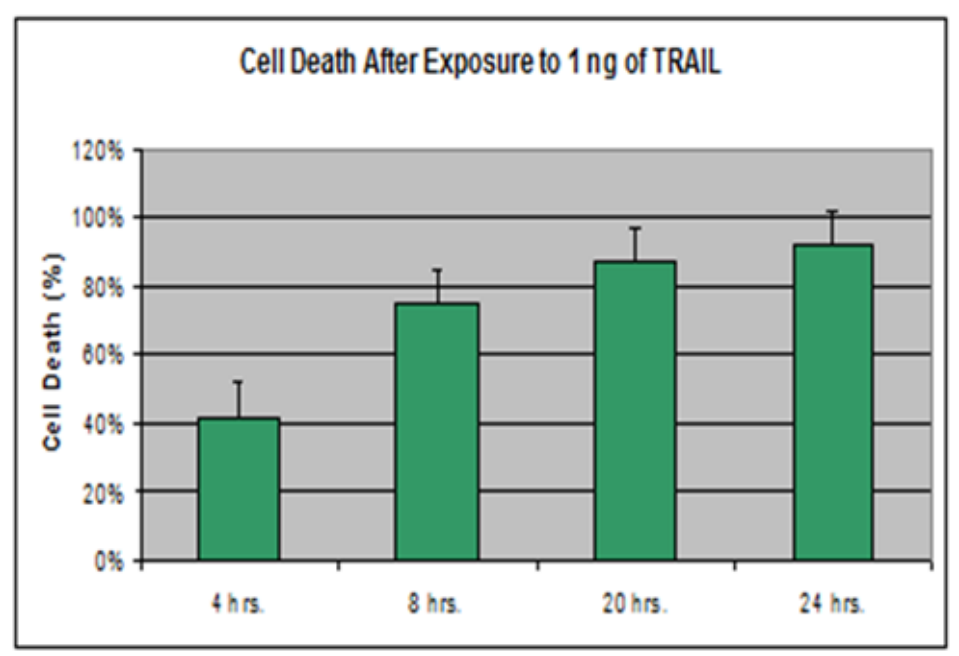

Figure 3. HTB-12 cell death after exposure to $1 \mathrm{ng} / \mathrm{ml}$ of TRAIL for various time periods at $37^{\circ} \mathrm{C}$. After $4,8,20$, and 24 hour treatments, cell death was assayed using the Trypan Blue Exclusion Method and direct count using a hemocytometer. Four and 24 hour means are statistically different from each other (t-Test, $\alpha=0.05$ ) (Table 3). 
Three concentrations of TRAIL were used in this study ranging from $0 \mathrm{ng} / \mathrm{ml}$ to $200 \mathrm{ng} / \mathrm{ml}$. The range of concentrations that were used was based on previous studies concerning TRAIL and glioma cells ${ }^{[17-20]}$. In this study, $1 \mathrm{ng} / \mathrm{ml}$ of TRAIL (Figure 2) caused 42\% HTB-12 cell death at 4 hours. This concentration was closest to the IC50 value for this HTB-12 astrocytoma cell line. Treatments using $1 \mathrm{ng}$ of TRAIL for time periods ranging from 0 to 24 hours showed a gradual increase in cell death over time (Figure 3).

Table 2. Effects of various concentrations of TRAIL on HTB- 12 after 4 hours at $37^{\circ} \mathrm{C}$. Analysis conducted using one way ANOVA and t-Test $(\alpha=0.05)$. Means with the same letter are not significantly different.

\begin{tabular}{ll}
\hline Treatment & Mean \pm std. \\
TRAIL (ng/ml) & $37.53 \pm 0.5 \mathrm{a}$ \\
\hline 0 & $72.57 \pm 0.1 \mathrm{~b}$ \\
1 & $87.53 \pm 0.5 \mathrm{c}$ \\
100 & $157.00 \pm 0.1 \mathrm{~d}$ \\
\hline
\end{tabular}

Table 3. HTB-12 cell death after exposure to $1 \mathrm{ng} / \mathrm{ml}$ TRAIL from 4 to 24 hours at $37^{\circ} \mathrm{C}$. Analysis conducted using one way ANOVA and t-Test $(\alpha=0.05)$. Means with the same letter are not significantly different.

\begin{tabular}{ll}
\hline Treatment & Mean \pm std. \\
Time (Hours) & $82.5 \pm 5.0 \mathrm{a}$ \\
\hline 4 & $103.1 \pm 7.7 \mathrm{ab}$ \\
8 & $110.7 \pm 0.1 \mathrm{ab}$ \\
20 & $115.1 \pm 4.1 \mathrm{~b}$ \\
\hline
\end{tabular}

\section{Discussion}

TRAIL is currently being studied as a possible treatment for cancer. TRAIL has been studied in brain, breast, prostate, liver and cervical cancer ${ }^{[5,6,8]}$. Death receptors for TRAIL have been found in various tissues, including those with normal and cancerous cells ${ }^{[8]}$. In cancerous cells, TRAIL causes apoptosis, which is why many researchers have begun investigating the use of TRAIL as a potential chemotherapeutic treatment. Studies have shown that TRAIL alone can lead to cancer cell deaths, but TRAIL along with a conventional chemotherapeutic agent can lead to greater numbers of cell deaths ${ }^{[21]}$. Unlike chemotherapeutic agents and radiation, which need the activation of the p53 tumor suppressor gene, TRAIL and other death ligands induce apoptosis in the cell whether or not $\mathrm{p} 53$ is activated ${ }^{[21]}$. like other members of the TNF family, TRAIL has been found not to have such severe side effects within normal tissues. TNF has been shown to cause a lethal inflammatory response, and Fas-induced apoptosis has been shown to cause lethal damage in the liver ${ }^{[21]}$.

Researchers initially thought that TRAIL could be cytotoxic, but due to its expression in a wide variety of tissues and its resistance in normal tissues they have dismissed this idea. For example, TRAIL was studied in mice with intracranial gliomas. The mice were treated with various doses of TRAIL ranging from $0.3 \mathrm{~kg} / \mathrm{mg}$ to $30 \mathrm{~kg} / \mathrm{mg}$ per day for 7 days. Researchers in this study concluded that there was no sign of toxicity when the mice were treated with the highest dose of TRAIL. Furthermore, TRAIL at $30 \mathrm{~kg} / \mathrm{mg}$ did not impact normal cells and inhibited tumors and none of the animals displayed neurological problems or weight gain issues ${ }^{[1]}$.

Pure cultures of normal fetal human astrocytes were investigated for the presence of DR4 and DR5 receptors on the cell surface, whether DR4 or DR5 protein was present in the astrocytes and whether DR4 or DR5 sequence was expressed in mRNA. The researchers concluded that both receptors were found in the astrocytes and on the cell surface with DR5 
expressed more than DR4. Results showed that DR4 and DR5 expression were less pronounced in astrocytes when compared to the experimental controls human glioma cell line U343MG and the human lung cancer cell line A549 ${ }^{[22]}$.

The actual apoptosis pathway via TRAIL binding DR4 or DR5 receptors can precede in either an extrinsic or intrinsic fashion. Both of these receptors contain cysteine-rich pseudo-repeats, which allow TRAIL to bind and recruit the intracellular adaptor Fas-associated death domain (FADD) ${ }^{[23]}$. Through the addition of FADD, the protease caspase-8 is recruited, causing the formation of a death inducing signaling complex (DISC). With the formation of DISC, caspase- 8 is cleaved, which can either cleave caspase-3 to activate the extrinsic pathway, or cleave Bid, a member of the Bcl-2 family, to activate the intrinsic pathway ${ }^{[5,23]}$. Caspase 3 will then activate substrates leading to apoptosis, such as DNA fragmentation factor 45 , which is an inhibitor of nuclease activity activated by caspases, leading to its removal from DNA fragmentation factor 40 , which is a nuclease activated by caspases. This will then lead to the cell shrinking and destruction of chromosomes and cell nucleus ${ }^{[24,25]}$. Glioma cells have also been found to express low or undetectable level of decoy receptors DcR1and DcR2. These receptors do not contain the cytoplasmic death domain ${ }^{[8,11-13]}$. There is not enough expression to inhibit the formation of DISC, which consists of caspase- 8 and FADD, within the cell to initiate apoptosis. DISC is required to begin the process of apoptosis after the binding of TRAIL to its death receptors ${ }^{[1,18,26]}$.

A study was conducted regarding the effects of TRAIL on thirteen glioma cell lines and normal astrocytes. All cell lines including primary astrocytes were treated with the maximum dose of $300 \mathrm{ng} / \mathrm{ml}$ TRAIL. Three of the glioma cell lines were sensitive, ten were resistant and normal astrocytes were resistant ${ }^{[18]}$. Since TRAIL can selectively kill cancer cells without harming normal cells ${ }^{[21]}$, we searched for the presence of DR4 and DR5 death receptors in the HTB-12 astrocytoma cell lines and studied the effect of different doses of the drug at different time points.

In this study, we found that HTB-12 astrocytoma cell lines expresses DR4 and DR5 receptors and are sensitive to TRAIL treatment, whereas normal human astrocytes have a very low expression of these receptors and are resistant to TRAIL. Thus, TRAIL could be an effective therapeutic agent for treatment of this type of cancers by selectively targeting the brain cancer cells respiting the normal healthy cells. However, more cell lines have to be tested and animal models examined before any final conclusion can be drawn.

\section{Acknowledgement}

This research was supported by NSF-LSAMP grant and NIH-RISE grant \#GM08280804 to Elizabeth City State University campus of The University of North Carolina.

\section{References}

[1] Pollack I, Erff M, Ashkenazi A. Direct stimulation of apoptotic signaling by soluble Apo2L/ tumor necrosis factor-related apoptosis-inducing ligand leads to selective killing of glioma cells. Clin Can Res. 2001; 7: 1362-1369.

[2] Hanahan D, Weinberg R. The hallmarks of cancer. Cell. 2000; 100: 57-70.

[3] Boon K, Edwards J, Eberhart C, Riggins G. Identification of astrocytoma associated genes including cell surface markers. BMC Cancer. 2004; 4: 32.

[4] Pitti R, Marsters S, Ruppert S, Donahue C, Moore A, Ashkenzai A. Induction of apoptosis by Apo-2 ligand, a new member of the tumor necrosis factor cytokine family. J Biol Chem. 1996; 271: 12687-12690.

[5] Song J, Song D, Pyrzynska B, Petruk K, Van Meir E, Hao C. TRAIL triggers apoptosis in human malignant glioma cells through extrinsic and intrinsic pathways. Brain Pathol. 2003; 13: 539-553.

[6] Zerafa N, Westwood J, Cretney E, Mitchell S, Waring P, Iezzi M, Smyth M. Cutting edge: TRAIL deficiency accelerates hematological malignancies. Journal of Immunology. 2005; 175: 5586-5590.

[7] Wiley S, Schooley K, Smolak P, Din W, Huang C, Nicholl J, Sutherland G, Smith T, Rauch C, Smith C, Goodwin R. Identification and characterization of a new member of the TNF family that induces apoptosis. Immunity. 1995; 3: 673-682.

[8] Ryu H, Chang K, Chang S, Kim M, Joo H, Oh K. Expression of TRAIL (TNFrelated apoptosis-inducing ligand) receptors in cervical cancer. Int J Gynecol Cancer. 2000; 10: 417-424. 
[9] Veselska R, Kuglik P, Cejpek P, Svachova H, Neradil J, Loja T, Relichova J. Nestin expression in the cell lines derived from glioblastoma multiforme. BMC Cancer. 2006; 6: 32.

[10] Walczak H, Degli-Esposti MA, Johnson RS, Smolak PJ, Waugh JY, Boiani N, Timour MS, Gerhart MJ, Schooley KA, Smith CA, Goodwin RG, Rauch CT. TRAIL-R2: a novel apoptosis-mediating receptor for TRAIL. EMBO J. 1997;16(17):5386-5397.

[11] Schinder P, Bodmer J, Thome M, Hofmann K, Holler N, Tschopp J. Characterization of two receptors for TRAIL. FEBS. 1997; 416: 329-334.

[12] Degli-Esposti M, Smolak P, Walczak H, Waugh J, Huang C, DuBose R, Goodwin R, Smith C. Cloning and characterization of TRAIL-R3, a novel member of the emerging TRAIL receptor family. J. Exp. Med. 1997; 186(7): 1165-1170.

[13] Sheridan J, Marsters S, Pitti R, Gurney A, Skubatch M, Baldwin D, Ramakrichnan L, Gray C, Baker K, Wood W, Goddard A, Godowski P, Ashkenazi A. Control of TRAIL-Induced apoptosis by a family of signaling and decoy receptors. Science. 1997; 277: 818-820.

[14] Emery J, McDonnell P, Burke M, Deen K, Lyn S, Silverman C, Dul E, Appelbaum E, Fogh J, Fogh JM, Orfeo T. One hundred and twenty-seven cultured human tumor cell lines producing tumors in nude mice. J Natl Cancer Inst. 1977; 59(1): 221-226.

[15] Pan G, Ni J, Wei Y, Yu G, Gentz R, Dixit V. An antagonist decoy receptor and a death domain-containing receptor for TRAIL. Science. 1997; 277: 815-817.

[16] Wright W, Daniels W, Fogh J. Distinction of seventy-one cultured human tumor cell lines by polymorphic enzyme analysis. J Natl Cancer Inst. 1981; 66(2): 239-247.

[17] Kim K, Song J, An J, Kwon Y, Lee Y. Pretreatment of Acetylsalicylic Acid Promotes Tumor Necrosis Factor-related Apoptosis-inducing Ligand-induced Apoptosis by Down- regulating BCL-2 Gene Expression. Journal of Biological Chemistry 2005; 280(49): 41047-41055.

[18] Hao C, Beguinot F, Condorellli G, Trencia A, Van Meir E, Yong V, Parney I, Roa W, Jaganathan J, Petit J, Lazio B, Singh S, Chin L. Tumor necrosis factor-related apoptosis inducing ligand-mediated apoptosis in established and primary glioma cell lines. Neurosurg Focus. 2002; 13(3): 1-11.

[19] Jaganathan J, Petit JH, Lazio BE, Singh SK, Chin LS. Tumor necrosis factor-related apoptosis-inducing ligand-mediated apoptosis in established and primary glioma cell lines. Neurosurg Focus. 2002; 13(3): 1-11.

[20] Nagane M, Pan G, Weddle J, Dixit V, Cavenee W, Huang H. Increased death receptor 5 expression by chemotherapeutic agents in human gliomas causes synergistic cytotoxicty with tumor necrosis factor-related apoptosis-inducing ligand in Vitro and in Vivo. Cancer Res. 2000; 60: 847-853.

[21] Ashkenazi A, Pai R, Fong S, Leung S, Lawrence D, Marsters S, Blackie C,Chang L, McMurtrey A, Hebert A, DeForge L, Koumenis I, Lewis D, Harris L, Bussiere J, Koeppen H, Shahrokh Z, Schwall R. Safety and antitumor activity of recombinant soluble Apo2 ligand. J. Clin. Invest. 1999; 104(2): 155-162.

[22] Song J, Bellail A, Tse M, Yong V, Hao C. Human astrocytes are resistant to fas ligand and tumor necrosis factor-related apoptosis-inducing ligand-induced apoptosis. Journal of Neuroscience. 2006; 26(12): 3299-3308.

[23] Knight M, Riffkin C, Muscat A, Ashley D, Hawkins C. Analysis of FasL and TRAIL induced apoptosis pathways in glioma cells. Oncogene. 2001; 20(41): 5789-5798.

[24] Liu P, Nijhawan D, Budihardjo I, Srinivasula S, Ahmad M, Alnemri E, Wang X. Cytochrome c and dATP-dependent formation of Apaf-1/Caspase-9 complex initiates an apoptotic protease cascade. Cell. 1997; 91: 479-489.

[25] Zhang J, Wang X, Bove K, Xu M. DNA fragmentation factor 45-deficient cells are more resistant to apoptosis and exhibit different dying morphology than wild-type control cells. J Biol. Chem. 1999; 274(52): 37450-37454.

[26] Griffith T, Chin W, Jackson G, Lynch D, Kubin M. Intracellular regulation of TRAIL-induced apoptosis in human melanoma cells. J. Immunol. 1998; 161: 2833-2840. 